\title{
Enterobactérias em sistemas de tratamento aeróbio de resíduos sólidos orgânicos domiciliares
}

Esta pesquisa teve como objetivo avaliar a presença de enterobactérias em sistemas de tratamento aeróbio de resíduos sólidos orgânicos domiciliares. trabalho foi realizado em cinco etapas: contato com as famílias que praticam a coleta seletiva; estruturação e montagem da área experimental; desenvolvimento e adaptação de tecnologia para tratamento biológico aeróbio de resíduos sólidos orgânicos; coleta dos resíduos sólidos orgânicos nas residências e tratamentos dos resíduos sólidos orgânicos. Foram adotados dois modelos de tecnologia de tratamento: composteira de alumínio retangular (CAR) e composteira de polietileno cilíndrica (CPC). Durante o tratamento foi verificada a presença constante do grupo das bactérias Gram-negativas pertencente à família Enterobacteriaceae que persistiram até os últimos estágios da compostagem. O que representa alta capacidade de adaptação a diferentes condições do ambiente. Foram identificados nove gêneros e quinze espécies: Citrobacter (25,9\%), Enterobacter (14,1\%) Escherichia (11,7\%), Klebsiella (5,9\%), Morganella $(1,2 \%)$ Proteus $(35,4 \%)$, Providencia (1,2\%), Serratia (2,3\%), Salmonella (2,3\%). Observou-se que as maiores taxas de crescimento das enterobactérias ocorreram na fase mesofílica. As variações na densidade e diversidade das enterobactérias seguiram em conformidade com as mudanças das características físicas e químicas do substrato ao longo da compostagem. Portanto, de acordo com os dados coletados, há diversidade de enterobactérias nas diferentes fases do tratamento aeróbio de resíduos sólidos orgânicos domiciliares, correlacionando-se com as mudanças físicas e químicas do substrato.

Palavras-chave: Meio ambiente; Compostagem; Bactérias; Resíduos sólidos; Composto Orgânico.

\section{Enterobacteria in aerobic treatment systems for household organic solid waste}

This research aimed to evaluate the presence of enterobacteria in aerobic treatment systems for household solid organic waste. The work was carried out in five stages: contact with families that practice selective collection; structuring and assembly of the experimental area; development and adaptation of technology for aerobic biological treatment of organic solid waste; collection of solid organic residues in homes; treatment of organic solid waste. Two models of treatment technology were adopted: rectangular aluminum composter (CAR) and cylindrical polyethylene composter (CPC). During the treatment it was verified the constant presence of Gram-negative bacteria group of the group of Gram negative bacteria belonging to the Enterobacteriaceae family that persisted until the last stages of composting. This represents a high capacity to adapt to different environmental conditions. Nine genera and fifteen species were identified Citrobacter (25.9\%), Enterobacter (14.1\%) Escherichia (11.7\%), Klebsiella (5.9\%), Morganella (1.2\%) Proteus (35.4\%), Providencia (1.2\%), Serratia (2.3\%), Salmonella (2.3\%). It was observed that the highest growth rates of enterobacteria occurred in the mesophilic phase. The variations in density and diversity of Enterobacteria followed in line with changes in the physical and chemical characteristics of the substrate during composting. Therefore, according to the data collected, it was found that there is diversity of enterobacteria in the different phases of aerobic treatment of household solid organic waste, correlating with the physical and chemical changes of the substrate.

Keywords: Environment; Composting; Bacteria; Solid Waste; Organic compost.

Topic: Microbiologia Agrícola e Ambiental

Reviewed anonymously in the process of blind peer.

\section{Ivanise Gomes (iD)}

Universidade Estadual da Paraíba, Brasil http://lattes.cnpq.br/6042837219372011 http://orcid.org/0000-0003-4561-873 ivanisegomesbio@gmail.com

Monica Maria Pereira da Silva (iD Universidade Estadual da Paraíba, Brasil http://lattes.cnpq.br/8972860324282858 https://orcid.org/0000-0002-1593-1698 monicaea@terra.com.br

\section{Rosilene Barros Gomes (ic)}

Universidade Estadual da Paraíba, Brasil http://lattes.cnpq.br/0880366224800498 https://orcid.org/0000-0001-8086-8851 rosilene barrosgomes@hotmail.com

\author{
Adrianne Teixeira Barros (it) \\ Universidade Estadual da Paraíba, Brasil \\ http://lattes.cnpq.br/3228203365280543 \\ https://orcid.org/0000-0002-7393-642X \\ adriannebarros@yahoo.com.br \\ Fernando Luiz Barbosa Farias (id \\ Universidade Estadual da Paraíba, Brasil \\ http://lattes.cnpq.br/5564372426013611 \\ https://orcid.org/0000-0002-1894-6481 \\ fernando.luiz.2327@gmail.com \\ Patrícia Maria de Freitas e Silva (it \\ Universidade Estadual da Paraíba, Brasil \\ http://lattes.cnpq.br/6585228412816059 \\ https://orcid.org/0000-0002-6961-0419 \\ patriciafritas.hemoibba@yahoo.com.br
}

\begin{abstract}
Karla Patrícia de Oliveira Luna
Universidade Estadual da Paraíba, Brasil http://lattes.cnpq.br/3043580578707915 https://orcid.org/0000-0002-2746-6973 karlaceatox@yahoo.com.br

Beatriz Susana Ovruski de Ceballos (iD) Universidade Estadual da Paraíba, Brasil http://lattes.cnpq.br/9321950498637802 https://orcid.org/0000-0003-0458-4667 bia.ceballos@gmail.com

Elaine Cristina dos Santos Araújo (iD) Universidade Federal da Paraíba, Brasil http://lattes.cnpq.br/1224773257521776 https://orcid.org/0000-0002-6288-8469 cryslainne@gmail.com
\end{abstract}

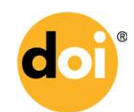

DOI: 10.6008/CBPC2179-6858.2021.005.0008

\section{Referencing this:}

GOMES, I.; SILVA, M. M. P.; GOMES, R. B.; BARROS, A. T.; FARIAS, F. L. B.; SILVA, P. M. F.; LUNA, K. P. O.; CEBALLOS, B. S. O.; ARAÚJO, E. C. S.. Enterobactérias em sistemas de tratamento aeróbio de resíduos sólidos orgânicos domiciliares. Revista Ibero Americana de Ciências Ambientais, v.12, n.5, p.77-93, 2021. DOI:

http://doi.org/10.6008/CBPC2179-6858.2021.005.0008 


\section{INTRODUÇÃO}

Existe uma grande difusão de ideias e conceitos a respeito da geração e danos causados pelos resíduos sólidos urbanos. A quantidade e a heterogeneidade de produtos, associada à facilidade de compra, tem influenciado direta e indiretamente as pessoas a consumirem e descartarem cada vez mais rápido na medida em que surge uma nova novidade no mercado. Nesta visão, especialistas têm chamado atenção para os danos causados pela produção e consumo insustentáveis dos recursos ambientais e para o cuidado com o destino e a disposição final dos resíduos sólidos gerados.

Dentro dessa problemática, destacam-se os resíduos sólidos orgânicos, que correspondem aproximadamente a $52 \%$ dos resíduos gerados no país, que ainda não são tratados adequadamente. Essa quantidade de matéria orgânica que é descartada produz passivos ambientais que resultam em riscos e comprometem os recursos ambientais. Acarretam também agravos às esferas sociais e econômicas (CAMPITELLI, 2010; VILLAMIZAR, 2014; GAMA et al., 2019) e a saúde pública (SILVA, 2020).

Os altos índices de matéria orgânica que são produzidos proporcionam condições favoráveis ao desenvolvimento de vários organismos, dentre eles, agentes patogênicos. Reforçando-se que a disposição imprópria desses materiais favorece a proliferação de diversos vetores biológicos, tais como: moscas, mosquitos, baratas e ratos que neles encontram abrigo e alimento disponível. Esses organismos têm sido responsáveis pela disseminação de doenças entre animais e humanos, acarretando sérios problemas de saúde pública (BRASIL, 2013; CHAYB, 2015).

Torna-se evidente que o tratamento da fração orgânica é indispensável à eficiência da gestão ambiental das municipalidades brasileiras, tendo em vista os efeitos negativos sobre meio o ambiente e a saúde humana. Entre as várias opções de tratamento de resíduos sólidos, a compostagem em sistemas descentralizados tem sido vista como uma importante promessa na gestão de resíduos sólidos orgânicos (ARAÚJO et al., 2019; SILVA et al., 2020, ARAÚJO et al., 2021).

A compostagem é um sistema biológico de tratamento de resíduos sólidos sob condições controladas. Durante esse processo ocorrem transformações físicas, químicas e biológicas que envolvem a participação de diversos organismos (ARAÚJO et al., 2021). Especificamente, as bactérias, atuam como um dos principais responsáveis pela degradação da matéria orgânica, devido a sua alta capacidade de ocupar diferentes nichos ecológicos, desde ambientes aeróbios a anaeróbios até ambientes extremos como altas e baixas temperaturas, porém, alguns organismos envolvidos nesse processo podem ser patogênicos, a exemplo de enterobactérias, como cepas específicas de E. col enteropatogênico, Salmonella e Shigella.

Os membros da família Enterobacteriaceae são bastante citados durante os processos de compostagem de resíduos sólidos orgânicos domiciliares e em outros tipos de resíduos sólidos orgânicos (SUNDBERG et al.; 2010; JURADO et al.; 2014; WANG et al.; 2015; CERDA et al.; 2017; SOOBHANY et al.; 2017; SÁNCHEZ et al.; 2017). Neste viés, chama-se a atenção, para este tipo de resíduo, e a importância do tratamento, sem o qual, o lançamento no meio ambiente, constitui em risco potencial à saúde ambiental e humana.

A presença de enterobactérias nos resíduos sólidos orgânicos é um alerta, já que esse grupo de 
bactéria é um indicador internacional de contaminação fecal, como os coliformes termotolerantes, entre eles, a E. coli (APHA, 2005). Um ponto inquietante é o fato de algumas bactérias estarem entre os agentes patogênicos mais comuns que infectam seres humanos em todo mundo (GRAGERA, 2002).

Os resíduos sólidos orgânicos, embora detenham potencial para provocar impactos negativos sobre a saúde ambiental e humana, quando são tratados, transformam-se em fonte de nutrientes para os organismos autotróficos, mitigando-se grande parte de seus impactos adversos, além de possibilitar a ciclagem da matéria e o uso eficiente da energia (GOMES, 2019; Freitas et al., 2020; SILVA et al., 2020; ARAÚJO et al., 2021). Logo, o presente trabalho objetivou avaliar a presença de enterobactérias em sistemas de tratamento aeróbio de resíduos sólidos orgânicos domiciliares.

\section{METODOLOGIA}

\section{Caracterização da pesquisa e da área de estudo}

A execução deste trabalho teve por base a pesquisa quantitativa, do tipo experimental, que consiste na elaboração de instrumentos para coleta de dados, submetidos a testes, como mencionam Marconi e Lakatos (2011). A pesquisa foi desenvolvida no Laboratório do Grupo de Extensão e Pesquisa em Gestão e Educação Ambiental (LabGGEA) e no Laboratório de Microbiologia do Departamento de Biologia (UEPB), ambos situados no Centro de Ciências Biológicas e da Saúde (CCBS), da Universidade Estadual da Paraíba (UEPB), Campus I, localizado em Campina Grande-PB.

A coleta de dados foi realizada em cinco etapas: 1) Contato com as famílias praticantes da coleta seletiva; 2) Estruturação e montagem da área experimental; 3) Desenvolvimento e adaptação de sistemas de tratamento biológico aeróbio de resíduos sólidos orgânicos domiciliares; 4) Coleta de resíduos sólidos orgânicos domiciliares; 5) Monitoramento e avaliação dos sistemas de tratamento biológico aeróbio de resíduos sólidos orgânicos domiciliares.

\section{Procedimentos para Coleta de Dados}

Os resíduos sólidos orgânicos utilizados nesta pesquisa foram coletados separados dos demais resíduos nas residências situadas no bairro Malvinas, em Campina Grande, estado da Paraíba, Brasil. A escolha do bairro decorreu do processo de sensibilização, formação e de mobilização de diferentes atores sociais que vem sendo aplicado na área em estudo (NASCIMENTO, 2015; SOUSA, 2018; ARAÚJO et al., 2019; SILVA et al., 2019; SILVA et al., 2020).

O contato com as famílias foi feito de porta em porta com entrega de folhetos informativos sobre a pesquisa e resultados de demais trabalhos já realizados no bairro. Na oportunidade, foi respeitado o direito de cada indivíduo participar ou não do projeto. Esse momento ocorreu com ajuda de líderes comunitários e de uma Associação de catadores de materiais recicláveis que atua na área (GOMES, 2019).

A área experimental foi instalada ao lado do prédio das Três Marias, sendo denominada de Sistema de Tratamento Descentralizado Aeróbio de Resíduos Sólidos Orgânicos (SITRADERO). Este localizado no Campus I, da UEPB, modificado por Araújo (2018). Este abrange uma área de $16 \mathrm{~m}^{2}$, e sua estrutura é 
constituída por madeira, lona e telas de proteção (Figura 1). Esta estrutura tem por finalidade impedir interferências diretas da chuva e insolação, bem como a presença de animais, sobretudo de grande porte.

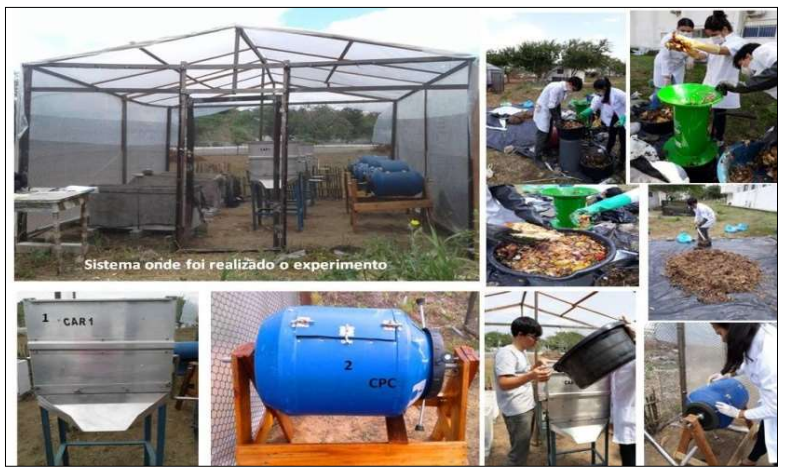

Figura 1: Sistema de Tratamento Biológico de Resíduos Sólidos Orgânicos Domiciliares- SITRADERO, Composteira de Alumínio Retangular - CAR e Composteira de Polietileno Cilíndrica - CPC e o processo de trituração dos resíduos sólidos orgânicos para montagem do experimento.

Para determinar o número de residências que constituiu a amostra para coleta dos resíduos sólidos orgânicos, Considerou-se o número de casas que havia aderido à coleta seletiva no bairro Malvinas, totalizando 283 residências. A partir desse número foi adotada uma amostragem aleatória, composto por 63 famílias, correspondendo a uma amostra de $22,6 \%$.

As coletas das amostras ocorreram durante um período de oito dias, seguindo-se o calendário da coleta do serviço público de limpeza urbana (terça-feira, quinta-feira e sábado). Foram coletados $330 \mathrm{~kg}$ de resíduos sólidos orgânicos. O total das amostras de resíduos sólidos orgânicos foi obtido a partir de quatro coletas. Os resíduos sólidos orgânicos foram coletados em sacos plásticos cedidos pela equipe de pesquisa. A parcela orgânica foi separada dos demais resíduos e encaminhada ao SITRADERO. Neste local, os resíduos sólidos orgânicos foram pesados e armazenados durante os oito dias que corresponderam ao período de coletas.

Os resíduos sólidos orgânicos domiciliares coletados foram bastante heterogêneos, desde cascas de frutas, legumes, restos de comida, ossos, pães, pó de café, folhas, palha e sabugos de milho e cascas de ovos. Após a caracterização, estes materiais foram triturados, visando reduzir o tamanho de suas partículas e obter granulometria favorável à ação dos organismos responsáveis pela degradação da matéria orgânica, sobretudo, dos microrganismos (SILVA, 2008).

As tecnologias em estudo foram constituídas por dois modelos de composteiras móveis em triplicata: composteira de alumínio e inox retangular - CAR (NASCIMENTO, 2015; ARAÙJO, 2018; ARAÚJO et al., 2019; SILVA et al., 2019; GOMES et al., 2021) e composteira de polietileno cilíndrica-CPC (GOMES, 2019; GOMES et al., 2021), como mostram as Figuras 2 e 3.

Os tratamentos foram aplicados em triplicata: $\mathrm{CAR}_{1}, \mathrm{CAR}_{2}$ e $\mathrm{CAR}_{3} ; \mathrm{CPC}_{1} \mathrm{CPC}_{2}$ e $\mathrm{CPC}_{3}$ (Quadro 1). Cada composteira foi alimentada com $26,6 \mathrm{~kg}$ de substratos triturados. Desse total, $80 \%$ foram resíduos sólidos orgânicos domiciliares e $20 \%$ de estruturantes. Estes foram compostos por folhas, adubo tipo farelo e rejeito (material orgânico que não foi totalmente degradado em outros experimentos). As dimensões das composteiras estão apresentadas no Quadro 1. 


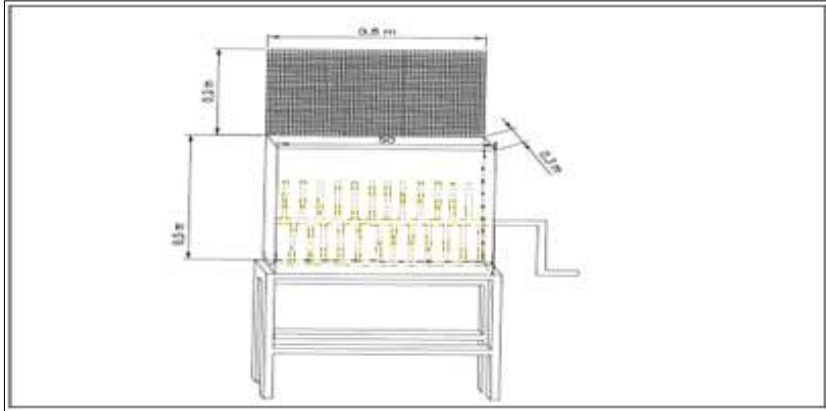

Figura 2: Desenho esquemático da composteira de alumino e inox retangular (CAR). Fonte: NASCIMENTO (2015); GOMES (2019).

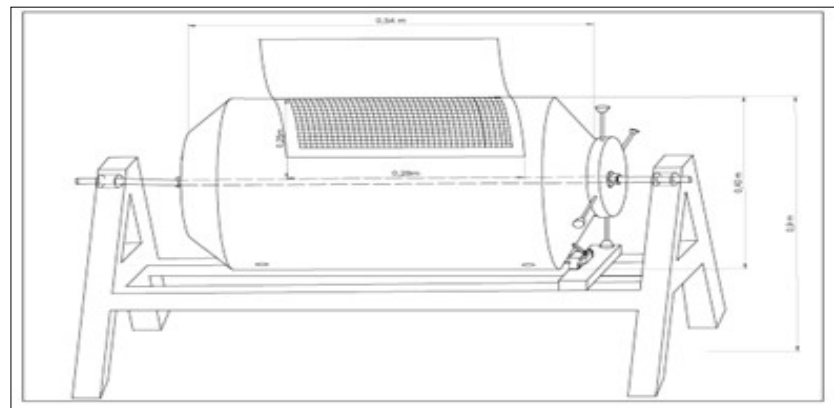

Figura 3: Desenho esquemático da composteira cilíndrica em polietileno (CPC). Fonte: GOMES (2019)

Quadro 1: Características dos modelos de tecnologias para tratamento biológico aeróbio de resíduos sólidos orgânicos domiciliares.

\begin{tabular}{|c|c|c|c|c|c|c|c|}
\hline \multirow[b]{2}{*}{ Siglas } & \multirow[b]{2}{*}{ Composteiras } & \multicolumn{3}{|c|}{ Dimensões (m) } & \multirow[b]{2}{*}{ Volume $\left(\mathrm{m}^{3}\right)$} & \multirow{2}{*}{$\begin{array}{c}\text { Capacidade de } \\
\text { carga } \\
\text { (kg) }\end{array}$} & \multirow[t]{2}{*}{ Subsistemas } \\
\hline & & $\mathbf{L}$ & c & $\mathbf{h}$ & & & \\
\hline \multirow[t]{2}{*}{ CAR } & $\begin{array}{l}\text { Aço inoxidável } \\
\text { retangular }\end{array}$ & 0,30 & 0,50 & 0,50 & $0,075 \mathrm{~m}^{3}$ & 30 & $\begin{array}{l}\mathrm{CAR}_{1} \\
\mathrm{CAR}_{2} \\
\mathrm{CAR}_{3}\end{array}$ \\
\hline & & & & & & & $\mathrm{CPC}_{1}$ \\
\hline \multirow[t]{2}{*}{ CPC } & Polietileno cilíndrico & 0,30 & 0,54 & 0,40 & $0,04 \mathrm{~m}^{3}$ & 30 & $\mathrm{CPC}_{2}$ \\
\hline & & & & & & & $\mathrm{CPC}_{3}$ \\
\hline
\end{tabular}

L- largura c- comprimento h-altura

O monitoramento dos sistemas de tratamento foi realizado a partir das análises físicas, químicas e biológicas dos resíduos sólidos orgânicos domiciliares, as quais foram realizadas no LabGGEA e no Laboratório de Microbiologia do Departamento de Biologia (UEPB), ambos situados CCBS/UEPB, Campus I e no laboratório do Setor de Ciências do Solo da Universidade Federal da Paraíba (UFPB), na cidade de Areia-

PB. Os parâmetros estudados estão descritos no quadro 2.

Quadro 2: Caracterização física, química e biológica dos resíduos sólidos orgânicos domiciliares.

\begin{tabular}{|c|c|c|c|c|}
\hline & Parâmetros & Frequência & Método Utilizado & Fonte \\
\hline \multirow[t]{4}{*}{ Físico } & Temperatura $\left({ }^{\circ} \mathrm{C}\right)$ & $\begin{array}{l}\text { Diariamente até } 15^{\circ} \text { dia } \\
\text { Semanal }\end{array}$ & Aferição por termômetro mercúrio & APHA (2005) \\
\hline & Teor de umidade (\%) & Semanal & Gravimétrico & Goldin (1987) \\
\hline & $\mathrm{pH}$ (Unidade) & Semanal & Potenciométrico & APHA (2005) \\
\hline & Carbono Orgânico Total (\%ST) & Inicial e Final & Kiehl (1998) 1,8xSTV & Goldin (1987) \\
\hline \multirow{4}{*}{ Químico } & Sólidos Totais Voláteis (\%ST) & Semanal & Gravimétrico & Silva (2008) \\
\hline & Potássio (\%ST) & Inicial e Final & Fotometria de chama & Okumura et al.; (2004) \\
\hline & Nitrogênio total (\%ST) & Inicial e Final & Método Kjeldhal & Tedesco et al., (1995) \\
\hline & Fósforo Total (\%ST) & Inicial e Final & Espectrofotométrico com ácido ascórbico & Tedesco et al., (1995) \\
\hline Biológico & Ovos de Helmintos (ovos/gST) & Inicial e Final & Meyer (1978) adaptado por Silva (2008) & Silva (2008) \\
\hline
\end{tabular}

\section{Caracterização biológica e qualidade sanitária dos resíduos orgânicos domiciliares}

A qualidade sanitária foi feita por meio da análise qualitativa e quantitativa de bactérias da família 
Enterobacteriaceae. Para caracterizar a diversidade de enterobactérias no processo de compostagem, foram monitorados os sistemas de tratamento (composteiras) desde a fase inicial (montagem) até o final do processo. As amostras foram coletadas semanalmente de agosto a novembro de 2018, perfazendo um total de dez coletas. Para obtenção das amostras, foram coletadas pequenas alíquotas em diferentes pontos e profundidade para formarem uma amostra de aproximadamente $10 \mathrm{~g}$ (JURADO et al., 2014). Este material foi armazenado e ligeiramente homogeneizado em sacos plásticos com zíper e encaminhado ao laboratório onde foram processados.

As análises microbiológicas foram realizadas usando o método de diluição seriada decimal, conforme Instrução Normativa do Ministério da Agricultura, Pecuária e Abastecimento no 30 de 12/11/2010 (BRASIL, 2010). Inicialmente, foi produzida uma suspensão de $10 \mathrm{~g}$ de resíduo bruto em $90 \mathrm{~mL}$ de solução fisiológica estéril a $0,9 \%$ e filtrada em filtro de polietileno. A partir desta suspensão, foram preparadas diluições seriadas até $10^{-5}$, transferindo-se $1 \mathrm{~mL}$ da diluição anterior para outros $9 \mathrm{~mL}$ de solução fisiológica estéril a $0,9 \%$. Após cada diluição foram descartadas as pipetas e os procedimentos foram realizados sob condições assépticas. Foram utilizados os meios de cultura Agar MacConkey para isolamento e contagem de Enterobactérias; Agar SS foi adotado para isolamento de espécies dos gêneros Salmonella e Shigella (BRASIL, 2011; OPLUSTIL et al.; 2010; CHANDNA et al.; 2013).

Foram distribuídos $100 \mu \mathrm{l}$ das diluições $10^{4}$ e $10^{5}$, em duplicata, através da técnica de espalhamento com a alça Drigalski, em placas de Petri, contendo cada um dos meios citados anteriormente. Realizada a inoculação, as placas foram invertidas e incubadas a 35-37ㅇ C por 24 horas em estufa bacteriológica. Após esse período as colônias foram contadas e as populações expressas em termos de UFC ${ }^{-1}$.

Para o cálculo do total das colônias foi aplicada a média da contagem das placas em duplicata semeadas com alíquotas de cada uma das diluições; o resultado foi multiplicado pelo fator da diluição da amostra. Foram contadas as placas que apresentavam um número de colônias entre 30 a 300 UFC. Foram repicadas duas colônias morfologicamente diferentes de cada placa contendo os meios MacConkey e Ágar SS. Após a purificação, as culturas passaram por uma bateria de provas bioquímicas para identificação dos principais gêneros e espécies presentes.

A determinação dos gêneros e das espécies isoladas foi realizada com uso de kits específicos para Enterobactérias, contendo diferentes meios de cultura. Os testes bioquímicos incluíam o uso do Meio EPM: que permite avaliar a produção de gás a partir da glicose, produção de gás sulfídrico $\left(\mathrm{H}_{2} \mathrm{~S}\right)$, hidrólise da ureia e desaminação do triptofano, o Meio MIO para motilidade, indol e ornitina, o Meio RHAMNOSE, o Meio LMI: para lisina, Motilidade e indol e o Meio CITRATO DE SIMMONS, para visualizar o crescimento usando citrato como única fonte de carbono.

\section{Considerações Éticas}

A presente pesquisa foi desenvolvida mediante a aprovação e o consentimento dos participantes envolvidos, conforme descrito na resolução no. 466/2012 (BRASIL, 2012) do Conselho Nacional de Saúde/MS, que assegura os direitos e deveres da comunidade científica em relação aos sujeitos da pesquisa 
e ao Estado e dá continuidade às atividades desenvolvidas por Sousa (2018) e Araújo (2018). Destaca-se que o trabalho de Sousa (2018) envolveu ações gerais aplicadas em conjunto com Araújo (2018), sendo submetido ao Comitê de Ética e aprovado por meio do parecer no 73948017.3.00005187.

\section{RESULTADOS E DISCUSSÃO}

\section{Caracterização dos resíduos sólidos orgânicos domiciliares}

Os resíduos sólidos orgânicos constituem uma fonte valiosa de nutrientes, podendo retornar ao ciclo produtivo quando submetido a tratamento. Do contrário, pode tornar-se uma fonte potencial danosa ao meio ambiente e à saúde pública. No cenário nacional e internacional, porém, ainda é dada pouca atenção a esse tipo de resíduo, concentrando-se no tratamento dos resíduos de serviço de saúde.

Conforme dados expostos na tabela 1, verifica-se que os resíduos sólidos orgânicos, embora tenham sido recolhidos diretamente das residências, apresentaram organismos que apontam para contaminação desses resíduos: ovos de helmintos (4,1 ovos/gST) e enterobactérias $\left(5,6 \times 10^{7}\right)$. Estes organismos encontram condições ideais para a sua sobrevivência, e em alguns casos, para a sua reprodução: alto teor de umidade e de sólidos totais voláteis (72\% e $83 \% \mathrm{ST}$, respectivamente), $\mathrm{pH}$ ácido $(5,2)$, carbono $(40 \% \mathrm{ST})$ e nutrientes, como $\mathrm{N}(1 \% \mathrm{ST})$.

Tabela 1: Caracterização sanitária dos resíduos sólidos orgânicos domiciliares submetidos ao tratamento aeróbio biológico.

\begin{tabular}{ll}
\hline Parâmetros & Valor \\
\hline pH & 5,2 \\
Teor de umidade (\%) & 72 \\
STV (\%ST) & 83 \\
COT (\%ST) & 40 \\
$\mathrm{~N}(\% S T)$ & 1 \\
$\mathrm{P}(\% \mathrm{ST})$ & 0,02 \\
$\mathrm{~K}(\% \mathrm{ST})$ & 0,02 \\
Ovos helmintos (ovos/gST) & 4,1 \\
Enterobactérias (UFC/g) & $5,6 \times 10^{7}$ \\
\hline
\end{tabular}

O número de ovos de helmintos identificado nos resíduos sólidos orgânicos estudados $(4,1$ ovos/gST), deve ser foco de debate e de preocupação, ao ponderar a dose infectante (1) e a sua alta resistência ao estresse ambiental, como afirma Neves (2005). Este dado reafirma o potencial de contaminação desse tipo de resíduo e chama a atenção para a importância de medidas em Educação Ambiental para o controle de doenças.

Resultados semelhantes foram encontrados por Silva et al. (2009) e Nascimento et al. (2017) que estudaram a prevalência de ovos de helmintos em resíduos sólidos orgânicos domiciliares em bairros situados em Campina Grande-PB. A presença de ovos de helmintos nos resíduos sólidos orgânicos é um ponto bastante preocupante, levando em consideração a alta incidência, a baixa dose infectante e a elevada resistência às condições ambientais adversas (METCALF et al., 2003, SILVA, 2008; SILVA et al, 2020).

Outro ponto preocupante é alta incidência de enterobactérias que pode indicar a presença de microrganismos patogênicos. Nos resíduos sólidos orgânicos coletados diretamente da fonte geradora 
foram encontrados valores médios de 5,6 x 107 UFC/g de enterobactérias. Dentre as bactérias Gramnegativas pertencentes à família Enterobacteriacea, foi registrada a prevalência dos gêneros Proteus $(35,4 \%)$, Citrobacter $(25,9 \%)$ e Enterobacter $(14,1 \%)$, correspondendo a $75,4 \%$ das enterobactérias identificadas.

A explicação para presença das enterobactérias nos resíduos sólidos orgânicos domiciliares é que estas já estavam presentes no produto alimentício original ou não foram cumpridas barreiras sanitárias. Pode-se também citar a irrigação com esgotos in natura dos produtos agrários usados pela população envolvida nesta pesquisa, uma prática bastante comum na região estudada, como atesta Silva (2008).

De acordo com Soobhany (2018), a presença de enterobactérias é um indicativo de possível presença de organismos patogênicos, o que pode tornar esses resíduos uma fonte potencialmente danosa ao meio ambiente e à saúde humana. Wu et al. (2018) ao estudarem as mudanças durante a deterioração dos resíduos sólidos orgânicos de origem alimentar, encontraram valores semelhantes de bactérias heterótrofas, $5,2 \times 10^{7} \mathrm{UFC} / \mathrm{g}^{-1}$.

O lançamento no meio ambiente de resíduos sólidos orgânicos sem nenhuma preocupação, simplesmente pelo fato de serem gerados em residências, constitui uma atitude imatura que contribui, sobretudo, para aumentar os problemas de saúde que atingem atualmente os seres humanos. Sabe-se, porém, que grande parte da sociedade humana, em especial dos gestores públicos, desconhece estas características, haja vista demonstração por parte destes, de maior preocupação com os resíduos de serviços de saúde.

A ausência de conhecimento sobre os resíduos sólidos de forma geral impõe o não cumprimento do que prevê o artigo 225 da Constituição Federal de 1988 (BRASIL, 1988), na Lei 9795/1999 (BRASIL, 1999) e na Lei 12.305/2010 (BRASIL, 2010), no que se refere ao papel da Educação Ambiental. É necessária a elaboração de programas em Educação Ambiental, por meio dos órgãos municipais competentes, de modo que a gestão integrada de resíduos sólidos seja posta em prática, favorecendo mudanças essenciais que contemplem o meio ambiente e à sociedade (SILVA, 2008; SILVA et al., 2020; 2020å).

\section{Análise físico-química dos resíduos sólidos orgânicos domiciliares}

A temperatura é um dos principais parâmetros de controle utilizado no processo de compostagem (WANG et al., 2015). A figura 3 mostra as variações que ocorreram nos sistemas CAR e CPC, durante o período de compostagem.

O valor médio da temperatura foi calculado a partir da aferição em nove pontos diferentes do material em cada sistema, alternando-as entre a superfície, centro e base. No início do experimento os valores de temperatura correspondentes aos nove pontos do substrato, encontraram-se baixos, próximos à temperatura ambiente para os sistemas CPC e CAR. Isso é presumível, devido ao alto teor de umidade registrado, o que reduz a permeabilidade do substrato, limitando assim, a atividade dos organismos aeróbios. 

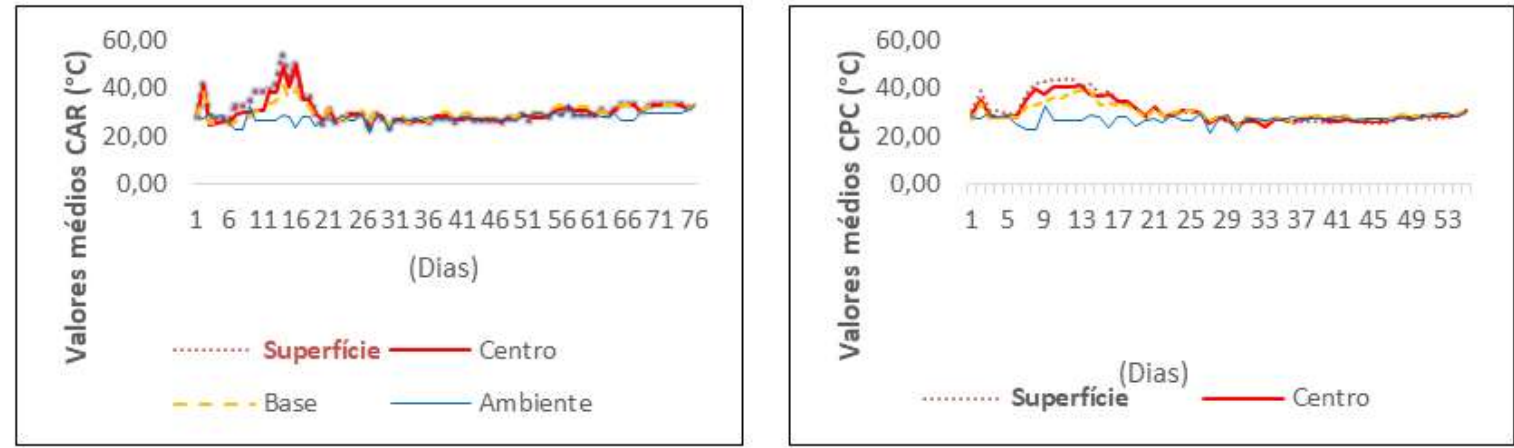

Figura 3: Níveis de Temperatura média registrada nos sistemas de tratamento de resíduos sólidos orgânicos domiciliares (CAR e CPC).

Os valores máximos de temperatura foram diferentes para os dois sistemas de tratamento de compostagem, indicando que a degradação e os organismos presentes no processo também variaram em consequência do material e da configuração das composteiras.

Do $13^{\circ}$ ao $18^{\circ}$ dia, as faixas de temperaturas médias registradas para os sistemas CAR variaram entre 40 e $50^{\circ} \mathrm{C}$, já para o sistema $\mathrm{CPC}$ as temperaturas médias variaram entre 40 e $43^{\circ} \mathrm{C}$. $\mathrm{O}$ sistema CAR alcançou as maiores faixas de temperatura, o que podem estar relacionadas ao tipo de sistema, bem como à atividade metabólica dos organismos presentes. Resultados similares foram encontrados por Chandna et al. (2013) ao avaliaram a diversidade bacteriana durante a compostagem de subprodutos agrícolas quando registraram faixas de temperatura entre 40 e $50^{\circ} \mathrm{C}$.

Segundo Wang et al. (2015), a diminuição da temperatura ocorre quando a atividade dos organismos é reduzida após esgotar todas as substâncias facilmente disponíveis. O sistema de tratamento CPC foi o primeiro a entrar na fase de maturação em um período de 56 dias. A umidade é essencial para atividade metabólica e fisiológica dos diferentes organismos presentes na compostagem. Margaritis et al. (2017) afirmam que os níveis baixos de umidade inibem a ação dos organismos, enquanto o excesso de umidade proporciona decomposição lenta e condições de anaerobiose durante a compostagem.

A umidade inicial registrada para ambos os sistemas de tratamento foi de $72 \%$ (Figura 4), valor considerado acima do ideal pela literatura (MARGARITIS et al., 2017). O alto teor de umidade constatado nesta pesquisa está relacionado à constituição dos resíduos sólidos orgânicos provenientes de ambientes domésticos, compostos basicamente de água, cascas de frutas, legumes e restos de comida.

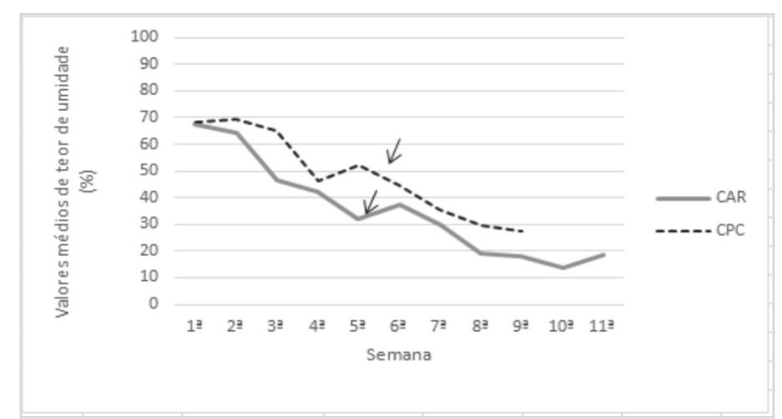

Figura 4: Valores médios referentes ao teor de umidade registrados nos sistemas de tratamentos de resíduos sólidos orgânicos domiciliares (CAR e CPC) - Setas indicam os dias em que foi adicionada água em cada sistema. Azul no sistema CAR; vermelho no sistema CPC. 
O alto teor de umidade não foi um problema para este tipo de tratamento (Figura 4), considerando as variações que ocorrem ao longo da compostagem por meio da atividade biológica dos organismos. As taxas altas de umidade também ajudaram a reduzir as taxas de evaporação ocasionadas pelas altas temperaturas ambientes da região, uma vez que os sistemas foram instalados em escala real. Os sistemas ficaram suscetíveis às variações da umidade relativa do ar, temperatura ambiente e exposição à radiação.

Resultados semelhantes foram encontrados por Wang et al. (2015) ao avaliarem a relação entre diversidade bacteriana e os parâmetros ambientais durante a compostagem de diferentes substratos, obtendo valores de umidade entre $73,19 \%$ a $77,32 \%$. Após o estágio que caracteriza a fase termófila, o teor de umidade foi substancialmente reduzido, pela ação dos organismos e pela evaporação da água, haja vista que foram registrados dias bastante quentes. Com isso, foi necessário adicionar 1,5 L de água em ambos os sistemas para regular a umidade.

No estágio final do processo, observou-se que a umidade caiu significativamente nas composteiras CAR, atingindo valor próximo a $19 \%$, enquanto nas composteiras CPC, atingiu valor próximo a $30 \%$. Essa redução influenciou na diversidade das enterobactérias em estudo, inibindo seu crescimento.

Os sistemas de tratamento CAR e CPC iniciaram com o pH de 5,23 (figura 5), indicando que os materiais em compostagem apresentavam caráter ácido. Segundo Gajalakshmi et al. (2008) o pH inicial é ácido, devido à degradação de compostos facilmente degradáveis e à formação de ácidos orgânicos.

A ação de diferentes organismos e subsequentemente oxidação do nitrogênio orgânico em nitrogênio amoniacal resulta no aumento do pH na compostagem (VALENTE et al., 2009). Na 3a semana do experimento, o pH aumentou chegando a níveis alcalinos, 8,23 para o sistema CAR e 8,49 para o sistema CPC, caracterizando a compostagem como um processo de mudanças rápidas, tendo vista as variações de $\mathrm{pH}$, umidade e temperatura que ocorreram em curto período (Figura 5).

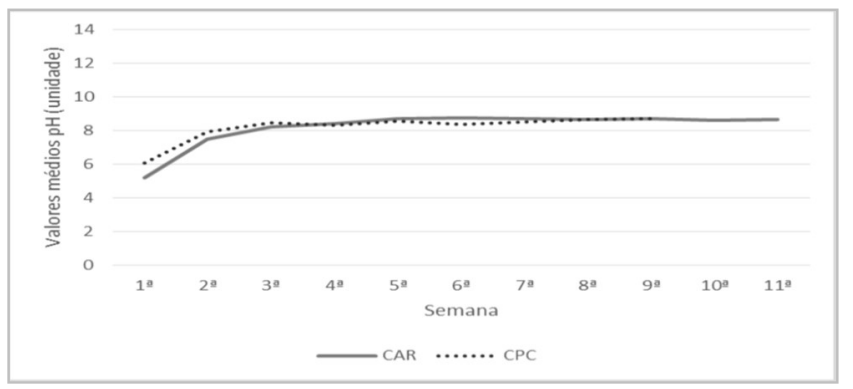

Figura 5: Valores de $\mathrm{pH}$ registrados nos sistemas de tratamento de resíduos sólidos orgânicos domiciliares (CAR e CPC).

No final da compostagem, quando o composto já apresentava níveis de estabilização, foram observados níveis de pH entre 8,69 e 8,75 para as composteiras CAR e CPC, respectivamente. O valor final do $\mathrm{pH}$ do composto é amplamente utilizado para avaliar a qualidade dos produtos de compostagem, porque influencia no $\mathrm{pH}$ do solo e na biodisponibilidade de nutrientes para plantas após a sua aplicação (WANG et al., 2015). No início da compostagem, os valores de sólidos totais voláteis observados foram de 83\% para os sistemas CAR e CPC. A partir da segunda semana foi observada a redução de sólidos totais voláteis, atingindo um percentual de 67,2\% para CAR e 65,1\% para CPC (Figura 6). 


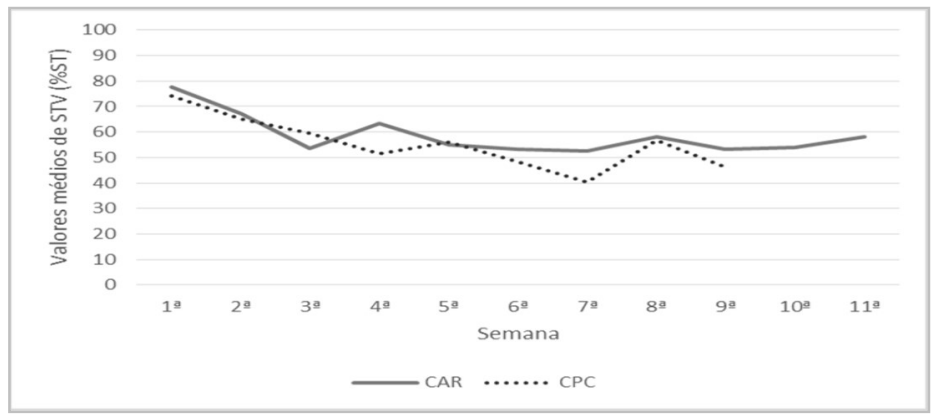

Figura 6: Valores médios de STV registrados em sistemas de tratamento de resíduos sólidos orgânicos domiciliares (CAR e CPC).

O decaimento gradual da matéria orgânica durante a compostagem mostra que nos sistemas de tratamento havia conteúdo orgânico facilmente degradável, como açúcares, proteínas e lipídios, o que resultou em maior atividade dos organismos presentes, aumentando a velocidade de estabilização do composto, como também constatou Silva (2008).

No final da compostagem foram verificados percentuais médios de $58 \%$ em CAR e $46,4 \%$ em CPC. Esses valores médios, associados aos baixos teores de umidade, refletiram diretamente na disponibilidade de nutrientes, limitando neste período, a atividade dos organismos, e possivelmente, a diversidade de enterobactérias, objeto de estudo desta pesquisa.

\section{Análise microbiológica dos resíduos sólidos orgânicos domiciliares}

O estudo dos organismos que participam da compostagem tem sido bastante relatado na literatura. A importância e o interesse por essa microbiota decorrem da sua capacidade de ocupar ambientes extremos e por apresentar diferentes funções no processo degradativo da matéria orgânica. Com exceção das bactérias do gênero Salmonella isoladas neste experimento, as quais são efetivamente patogênicas ao ser humano em quantidades a partir de $10^{5}$, as demais Enterobactérias isoladas, apesar de serem microrganismos que fazem parte da microbiota intestinal, podem ser potencialmente patogênicas para outros sítios anatômicos humanos (MICHAEL et al; 2016), principalmente considerando a elevada concentração de microrganismos encontrada no presente estudo. Caso contaminem uma pequena ferida na mão de um catador de material reciclável, por exemplo, podem causar infecção local, que se não for adequadamente tratada, desencadeia infecção generalizada (septicemia).

Importante ressaltar que as infecções por Enterobactérias são consideradas de difícil tratamento clínico, pois são microrganismos que apresentam elevada resistência aos antibióticos utilizados na prática médica, devido, entre outras razões, ao fato de serem capazes de produzir várias enzimas (ESBL, AmpC e carbapenemases) que degradam in vivo antibióticos como penicilinas e cefalosporinas.

Durante os estágios iniciais do processo de compostagem foi verificada pequena variação na densidade de enterobactérias nos sistemas CAR e CPC, conforme dados apresentados na tabela 2. A mudança na quantidade de enterobactérias nos dois sistemas reafirma que a configuração das composteiras e os parâmetros físicos, químicos e biológicos influenciam na densidade e diversidade de enterobactérias durante o processo de compostagem. 
Tabela 2: Valores médios referentes ao número de enterobactérias nos sistemas de tratamento de resíduos sólidos orgânicos domiciliares (CAR e CPC).

\begin{tabular}{|c|c|c|}
\hline \multirow{2}{*}{ Coletas } & \multicolumn{2}{|c|}{ Enterobactérias (UFC/g-1) } \\
\hline & Sistema (CAR) & Sistema CPC \\
\hline 1 & $8,1 \times 10^{7}$ & $7,9 \times 10^{7}$ \\
\hline 2 & $1,2 \times 10^{8}$ & $1,3 \times 10^{9}$ \\
\hline 3 & $6,9 \times 10^{7}$ & $7,8 \times 10^{7}$ \\
\hline 4 & $5,0 \times 10^{7}$ & $6,2 \times 10^{7}$ \\
\hline 5 & $1,7 \times 10^{7}$ & $2,7 \times 10^{7}$ \\
\hline 6 & $6,0 \times 10^{6}$ & $1,3 \times 10^{7}$ \\
\hline 7 & $3,0 \times 10^{6}$ & $5,0 \times 10^{6}$ \\
\hline 8 & $3,5 \times 10^{6}$ & $2,0 \times 10^{6}$ \\
\hline 9 & $1,5 \times 10^{6}$ & $1,0 \times 10^{6}$ \\
\hline 10 & 0 & 0 \\
\hline
\end{tabular}

Observou-se que o número máximo de enterobactérias ocorreu na fase mesófila. Esse aumento foi verificado a partir da segunda coleta da amostra. Foram registradas $1,2 \times 10^{8} \mathrm{UFC} / \mathrm{g}$ nos sistemas CAR e 1,3 x $10^{9} \mathrm{UFC} / \mathrm{g}$ no sistema CPC (Tabela 2). A disponibilidade de nutrientes e as condições favoráveis proporcionaram o crescimento dessas bactérias durante o processo.

Quando o processo de compostagem atingiu a fase mesófila, o número de enterobactérias visualizado nas amostras decresceu. A diminuição da densidade de enterobactérias continuou até a nona semana; no final da compostagem não foi detectado nenhum crescimento. Essa ausência está relacionada à depreciação dos nutrientes disponíveis e às mudanças dos parâmetros físicos e químicos durante a compostagem, decorridas da ação dos diferentes organismos autóctones. Nos estágios finais da compostagem, as condições tornaram-se limitantes ao desenvolvimento dessas bactérias devido a essas variações.

Considera-se que estes organismos são mesófilos e que toleram níveis de temperaturas abaixo da faixa de $45{ }^{\circ} \mathrm{C}$. A umidade também variou durante o processo, chegando a $19 \%$ para o sistema CAR e $30 \%$ para o sistema CPC. Outro fator limitante foi à quantidade de sólidos totais voláteis que decaiu gradualmente durante o processo, diminuída a quantidade de nutrientes disponíveis.

Chandna et al. (2013) que avaliaram a diversidade bacteriana durante a compostagem de subprodutos agrícolas, destacaram, em sua pesquisa, a ausência das enterobactérias no produto da compostagem. Para esses autores, este grupo de bactéria pode indicar presença de organismos patogênicos e tornar o composto impróprio para uso.

Este trabalho foi realizado em pequena escala, com resíduos domiciliares separados na fonte e acondicionados em sacos plásticos higienizados, o que deixa evidente que essas bactérias já estavam presentes no alimento in natura e se mantiveram ao longo da compostagem, estando ausentes apenas no final, indicando que essas bactérias atuam no processo degradativo da matéria orgânica, assim como, competem por nutrientes com outros grupos de organismos presentes na compostagem.

\section{Enterobactérias nos sistemas de tratamento aeróbio de resíduos sólidos orgânicos domiciliares.}

As enterobactérias foram isoladas e caracterizadas bioquimicamente, o que permitiu estabelecer um perfil dessas bactérias nas amostras coletadas. As espécies isoladas, do grupo das bactérias Gramnegativas pertenciam à família Enterobacteriaceae. Os resultados apresentados na tabela 3 e na figura 8 
apontam para a considerável diversidade desse grupo. Entre as 85 colônias isoladas neste trabalho, foram identificados 9 gêneros e entre eles, 15 espécies. Muitos dos gêneros identificados nesta pesquisa, também foram encontrados nos trabalhos de Chroni et al. (2008), Chandna et al. (2013), Jurado et al. (2014), Wang et al. (2015) e Cerda et al. (2017), ao estudarem a presença bacteriana durante o processo de compostagem de diferentes matérias primas.

Dos nove gêneros identificados, apenas o gênero Proteus permaneceu do início da compostagem até as fases finais. Não sendo encontrado apenas na última coleta. Os gêneros que apresentaram maior número de isolados foram Proteus (35,2\%), Citrobacter (25,9\%), Enterobacter (14,1\%) e Escherichia (11,8\%) que juntos correspondem a $87 \%$ do total de isolados.

Tabela 3: Total de espécies de enterobactérias e o número de isolado de cada gênero ao longo das coletas realizadas nos sistemas de tratamento de resíduos sólidos orgânicos domiciliares (CAR e CPC).

\begin{tabular}{|c|c|c|c|c|}
\hline \multirow{2}{*}{ Espécies } & \multicolumn{3}{|c|}{ № de colônias isoladas } & \multirow{2}{*}{$\%$} \\
\hline & CAR & CPC & Total & \\
\hline Citrobacter freudii & 5 & 4 & 9 & 10,6 \\
\hline Citrobacter diversus & 6 & 6 & 12 & 14,1 \\
\hline Citrobacter amalonaticus & 0 & 1 & 1 & 1,2 \\
\hline Enterobacter gergoviae & 3 & 3 & 6 & 7,1 \\
\hline Enterobacter aerogenes & 2 & 1 & 3 & 3,5 \\
\hline Enterobacter sakazakii & 1 & 0 & 1 & 1,2 \\
\hline Enterobacter cloacae & 0 & 2 & 2 & 2,3 \\
\hline Escherichia coli & 5 & 5 & 10 & 11,8 \\
\hline Klebisiella oxytoca & 2 & 3 & 5 & 6 \\
\hline Morganella spp & 0 & 1 & 1 & 1,2 \\
\hline Proteus mirabilis & 12 & 16 & 28 & 32,9 \\
\hline Proteus vulgaris & 0 & 2 & 2 & 2,3 \\
\hline Providencia spp. & 0 & 1 & 1 & 1,2 \\
\hline Serratia spp. & 1 & 1 & 2 & 2,3 \\
\hline Salmonella spp. & 2 & 0 & 2 & 2,3 \\
\hline Total & 39 & 46 & 85 & 100 \\
\hline
\end{tabular}
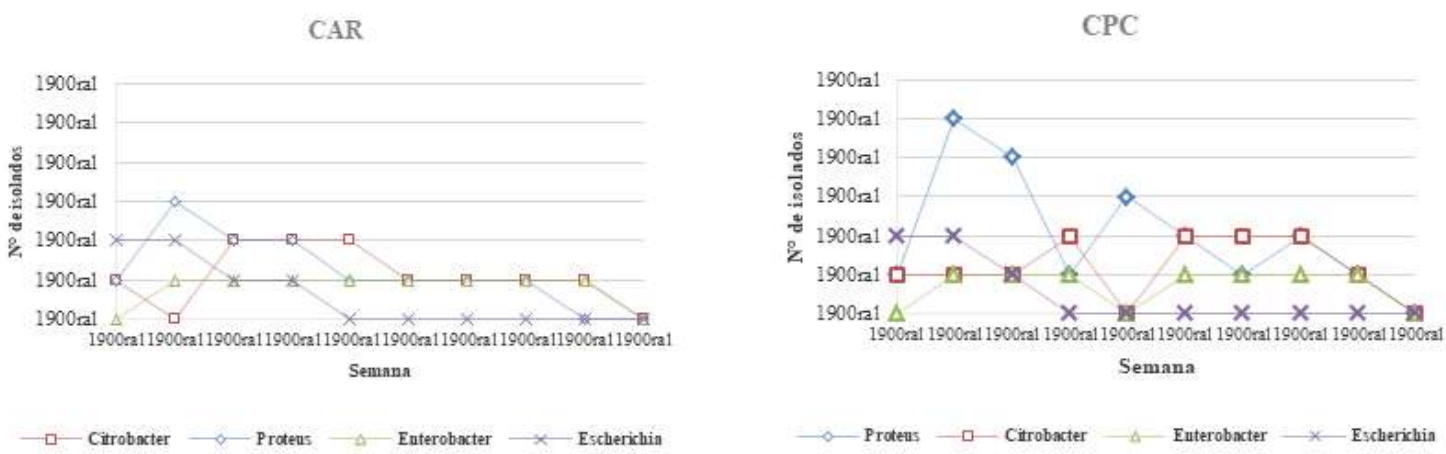

Figura 8: Número de gêneros, quantitativamente mais representativo, identificado nos sistemas de tratamento de resíduos sólidos orgânicos domiciliares (CAR e CPC)

Este resultado diferiu dos dados frequentemente encontrados na literatura (SUNDBERG et al., 2010; CHANDNA et al., 2013; WANG et al., 2015). Os gêneros comumente relatados são Enterobacter, Klebsiella e Escherichia spp. Em contraste, esta pesquisa identificou a predominância do gênero Proteus. Dentro desse gênero foram identificadas duas espécies Proteus mirabilis e Proteus vulgaris. Esses microrganismos estão associados a uma variedade de infecções. $P$. mirabilis é o mais frequentemente encontrado é responsável por 70\% a 90\% das infecções humanas causadas por Enterobactérias. Já Proteus vulgaris está relacionado à elevada resistência a antimicrobianos (KUSHWAHA; BABU; JUNEJA, 2014). 
A presença de Proteus spp. em resíduos sólidos orgânicos domiciliares é um indicativo para um microrganismo resistente, responsável pela degradação de diferentes matérias-primas na compostagem. Essas flutuações de gêneros e espécies de uma semana para outra podem ocorrer devido às mudanças dos parâmetros físico-químicos e a depreciação dos nutrientes disponíveis, além da sucessão ecológica que ocorre durante a compostagem.

No composto (adubo) não foi isolado nenhum grupo de bactéria da família Enterobacteriaceae. A baixa umidade, a falta de nutrientes e a competição com outros organismos na compostagem podem ter inibido o crescimento dessas bactérias. Através do índice de Shannon-Weaver foi calculada a diversidade de enterobactérias nas semanas de funcionamento da compostagem (Tabelas 4 e 5).

Tabela 4: Diversidade de enterobactérias por coleta no sistema de tratamento de resíduos sólidos orgânicos domiciliares CAR.

\begin{tabular}{cccccccccc}
\hline \multirow{2}{*}{ Enterobactérias } & C1 & C2 & C3 & C4 & C5 & C6 & C7 & C8 & C9 \\
\hline Gêneros & 4 & 4 & 4 & 3 & 4 & 3 & 3 & 3 & 2 \\
Espécie & 4 & 4 & 5 & 4 & 5 & 4 & 4 & 3 & 2 \\
Índice & 1,24 & 1,32 & 1,56 & 1,33 & 1,56 & 1,38 & 1,33 & 1,09 & 0,69 \\
\hline$*$ C- indica coletas semanais
\end{tabular}

Tabela 5: Diversidade de enterobactérias por coleta no sistema de tratamento de resíduos sólidos orgânicos domiciliares CPC.

\begin{tabular}{|c|c|c|c|c|c|c|c|c|c|}
\hline \multirow{2}{*}{ Enterobactérias } & \multicolumn{9}{|c|}{ CPC } \\
\hline & C1 & $\mathrm{C2}$ & C3 & C4 & C5 & C6 & C7 & C8 & C9 \\
\hline Gêneros & 4 & 2 & 4 & 5 & 4 & 3 & 4 & 2 & 3 \\
\hline Espécie & 5 & 2 & 4 & 5 & 5 & 4 & 5 & 3 & 3 \\
\hline Índice & 1,56 & 0,45 & 1,24 & 1,56 & 1,56 & 1,32 & 1,56 & 1,03 & 1,09 \\
\hline
\end{tabular}

${ }^{*} \mathrm{C}$ - indica coletas semanais

Observa-se que os índices variaram de 0,69 a 1,56 para o sistema CAR, e 0,45 a 1,56 para o sistema

CPC. A menor diversidade foi encontrada na segunda semana, no item C2 no sistema CPC, onde prevaleceu a incidência do gênero Proteus spp. Nas demais coletas, foi verificada maior heterogeneidade de gêneros. Nos estágios finais da compostagem foi constatada baixa ocorrência de números de isolados de gêneros e espécies. Os gêneros isolados que permaneceram até o final da compostagem são resistentes às variações físicas, químicas e biológicas que advieram durante a compostagem. Os gêneros quantitativamente dominantes foram Proteus, Citrobacter e Enterobacter.

\section{CONCLUSÕES}

Os resíduos sólidos orgânicos coletados separados diretamente da fonte geradora, as residências, apresentaram características físicas, químicas e sanitárias que refletem a necessidade de tratar estes resíduos antes de sua destinação final. $\mathrm{O}$ alto teor de umidade (72\%ST) e de sólidos totais voláteis (83\%ST), somados à quantidade de ovos de helmintos (4,1 ovos/gST) e de enterobactérias (5,6 x107 UFC/g) são características que evidenciam os problemas que podem ser acarretados quando este tipo de resíduo não é tratado.

Foram encontradas enterobactérias durante o processo de compostagem nos dois sistemas de 
tratamento, com pequenas variações para densidade enterobactérias entre os sistemas. A contagem desse grupo de bactéria foi de $8,1 \times 10^{7}$ a $1,5 \times 10^{6} \mathrm{UFC} \mathrm{g}{ }^{-1}$ para CAR e $1,2 \times 10^{7}$ a $1,0 \times 10^{6} \mathrm{UFC}^{-g^{-1}}$ para CPC. No produto, composto tipo pó, não foram registradas colônias de enterobactérias, apontando-se para o alcance de um dos objetivos da compostagem, a higienização ou sanitização.

Durante o período de tratamento, foi identificada uma considerável diversidade de enterobactérias, com variações entre os sistemas CAR e CPC. Entre as 85 colônias isoladas neste trabalho, 39 ocorreram no sistema CAR e 46 no sistema CPC, indicando que o material empregado e a configuração das composteiras influenciaram sobre densidade e diversidade de enterobactérias. Foram identificados nove gêneros e quinze espécies: Citrobacter (25,9 \%), Enterobacter (14,1\%) Escherichia (11,8\%), Klebsiella (6\%), Marganella (1,2\%) Proteus (35,2\%), Providencia (1,2\%), Serratia (2,3\%), Salmonella (2,3\%). Aponta-se que estas bactérias desempenham importante papel na degradação da matéria orgânica, favorecendo a estabilização do material em tratamento.

Constatou-se que as maiores taxas de crescimento das enterobactérias ocorreram na fase mesófila. As variações na densidade e diversidade das enterobactérias seguiram em conformidade com as mudanças das características físicas e químicas do substrato ao longo da compostagem. De acordo com os dados coletados, conclui-se que há diversidade de enterobactérias nas diferentes fases do tratamento aeróbio de resíduos sólidos orgânicos domiciliares, correlacionando-se com as mudanças físicas e químicas do substrato.

Neste sentido, esta pesquisa verificou alguns entraves e como forma de apurar novos cenários, recomenda-se: realizar novos estudos para verificar a resistência das enterobactérias durante a compostagem de resíduos sólidos orgânicos domiciliares; aprimorar os sistemas e otimizar o reviramento, de maneira que não haja necessidade da utilização de outros acessórios, como espátula, pá, dentre outros.

\section{REFERÊNCIAS}

ARAUJO, E. C. S.. Organismos que participam das diferentes fases do tratamento aeróbio de resíduos sólidos orgânicos domiciliares. Dissertação (Mestrado em Ciência e Tecnologia Ambiental) - Universidade Estadual da Paraíba, Campina Grande, 2018

ARAÚJO, E. C. S; SILVA, M. M. P; SILVA, A. V; SANTOS SOBRINHO, J. B.. Tratamento aeróbio de resíduos sólidos orgânicos domiciliares em sistemas descentralizados móveis. Congresso Brasileiro de Engenharia Sanitária e Ambiental. CONGRESSO BRASILEIRO DE ENGENHARIA SANITÁRIA E AMBIENTAL. Anais. Rio de Janeiro, 2019.

ARAÚJO, E. C. S.; SILVA, M. M. P.; SILVA, A. V.; BARROS, A. T.; LEITE, V. D.. Diversidade de mesoinvertebrados associada ao tratamento aeróbio de resíduos sólidos orgânicos domiciliares. Research, Society and Development, v.10, n.1, p.1-12, 2021.

APHA. American Public Health Association. Standard methods for the examination of water and wastewater. 21 ed. Washington, DC: APHA-WEF, 2005.

BRASIL. Lei 12.305/2010. Institui a Política Nacional de Resíduos Sólidos. Brasília: DOU, 2010.
BRASIL. Manual técnico de diagnóstico laboratorial de Salmonella spp. Ministério da Saúde, 2011.

BRASIL. Plano Nacional de Resíduos sólidos. Brasília: Ministério do Meio Ambiente, 2012.

BRASIL. Resíduos Sólidos e a Saúde da comunidade: informações técnicas sobre a interrelação saúde, meio ambiente e resíduos sólidos. Brasília: Fundação Nacional de Saúde- Funasa, 2013.

BRASIL. Compostagem doméstica comunitária e institucional de resíduos orgânicos: manual de orientação. Brasília: Ministério do Meio Ambiente, 2017.

CAMPITELLI, P.. Calidad de compost y vermicompuestos para su uso como enmiendas orgánicas en suelos agrícolas. Tese (Doutorado) - Universidade Nacional de Córdoba, Córdoba, 2010.

CERDA, A.; ARTOLA, A.; FONT, X.; BARRENA, R.; GEA, T.; SÁNCHEZ, A.. Composting of food wastes: status and challenges. Bioresource Technology, v.248, p.57-67, 2017. 
CHAYB, E. F.. Estudo comparativo da contaminação por micro-organismos patogênicos em resíduos sólidos domiciliares e de saúde em Uberlândia. Dissertação (Mestrado em Ciências Ambientais) - Universidade Camilo Castelo Branco, 2014.

CHRONI, C.; KYRIACOU, A.; MANIOS, T.; LASARIDI, K. E.; Investigation of the microbial community structure and activity as indicators of compost stability and composting process evolution. Bioresource Technology, v.100, p.37453750,2008

CHANDNA, P.; NAIN, L.; SINGH, S.; KUHAD, R. C.. Assessment of bacterial diversity during composting of agricultural by products. BMC Microbiology, v.13, n.99, p.1-14, 2013.

FREITAS, A. F.; LEITE, V. D.; SILVA, M. M. P.; GOMES, R. B.; SILVA, M. J.; FARIAS, F. L. B.; BARROS, A. T.. Tratamento aeróbio de resíduos sólidos orgânicos gerados em condomínio vertical como alternativa sustentável. Research, Society and Development, v.9, n.10, p.1-27, 2020.

GRAGERA, A. B.. Infecciones por enterobacterias. Elservier, v.8, p.3385-3397, 2002.

GAMA, A. M. C. F.; COSTA, V. C. B.; FIRMO, A. B. L.; JUCÁ, J F. T.. Estudo das emissões de GEE da disposição de resíduos sólidos na região metropolitana do Recife. Revista IberoAmericana de Ciências Ambientais, v.10, n.6, p.163-177, 2019.

GOLDIN, A.. Reassessing the use of loss-on-ignition for estimating organic matter content in noncalcareous soils. Commun. Soil Science. Plant, n.18, p.1111-1116, 1987.

GAJALAKSHMI, S., ABBASI, S. A.. Solid waste management by composting: state of the art. Critical Reviews in

Environmental, Science and Technology, v.38, n.5, p.311400, 2008

GOMES, I.. Comportamento de Enterobactérias em Sistemas de Tratamento Aeróbio Descentralizado de Resíduos Sólidos Orgânicos Domiciliares. Dissertação (Mestrado em Ciência e Tecnologia Ambiental) Universidade Estadual da Paraíba, Campina Grande, 2019.

GOMES, I.; SILVA, M. M. P.; GOMES, R. B.; FARIAS, F. L. B.; ARAUJO, E. C. S.; BARROS, A. T.. Tecnologia para tratamento aeróbio de Resíduos Sólidos Orgânicos Domiciliares. Revista Ibero-Americana de Ciências Ambientais, v.12, n.1, 2021.

JURADO, M.; LÓPEZ, M. J.; SUÁREZ-ESTRELLA, F.; VARGASGARCÍA, M. C.; LÓPEZ-GONZÁLEZ, J. A.; MORENO, J.. Exploiting composting biodiversity: Study of the persistent and biotechnologically relevant microorganisms from lignocellulose-based composting. Bioresource Technology, v.162, p.283-293, 2014.

KUSHWAHA, K.; BABU, D.; JUNEJA, K.. Proteus. Food science, v.2, p.238-243, 2014

METCALF; EDDY. Wastewater engineer treatment disposal, reuse. 4 ed. New York: McGRaw- Hill Book, 2003.

MARCONI, M. A.; LAKATOS, E. M.. Técnicas de Pesquisa: planejamento e execução de pesquisas amostragens e técnicas de pesquisa, elaboração, análise e interpretação de dados. 4 ed. São Paulo: Atlas, 1999.
MICHAEL, M.; MARTINKO, J. M.; BENDER, K. S.; BUCKLEY, D. H.; STAHL, D. A.; FONSECA, F. G.. Microbiologia de Brock. 14 ed. Porto Alegre: Artmed, 2016.

MARGARITIS, M.; PSARRAS, K.; PANARETOU, V.; THANOS, A. G.; MALAMIS, D.; SOTIROPOULOS, A.. Improvement of home composting process of food waste using different minerals. Waste Management, v.73, p.87-100, 2017.

NEVES, D. P.. Hymenolepis nana. In NEVES, D. P.; MELO, A. L.; LINARDI, P. M.; VITOR, R. W. A.. Parasitologia Humana. 11 ed. São Paulo: Atheneu, 2005, p.494.

\section{NASCIMENTO, C. R.. Alternativas tecnológicas para} viabilização do exercício profissional e inclusão social de catadores de materiais recicláveis. Dissertação (Mestrado em Ciência e Tecnologia Ambiental) - Universidade Estadual da Paraíba, Campina Grande, 2015.

NASCIMENTO, R.; SILVA, M. M. P.; ARAUJO, E. C. S.; COSTA, M. P.; SILVA, A. V.. Avaliação de sistema de tratamento aeróbio descentralizado móvel de resíduos sólidos orgânicos domiciliares no bairro Malvinas, Campina Grande-PB. In: CONGRESSO BRASILEIRO DE ENGENHARIA SANITÁRIA E AMBIENTAL. Anais. São Paulo, Associação Brasileira de Engenharia Sanitária e Ambiental-ABES, 2017.

OKUMURA, F.; CAVALHEIRO, E. T. G.; NOBREGA, J. A. Química nova, v.27, p.832-836, 2004.

OPLUSTIL, C. P.; ZOCCOLI, C. M.; TOBUTI, N. R.; SINTO, S. I.. Procedimentos básicos em microbiologia clínica. 3 ed. São Paulo: Sarvier, 2010.

SÁNCHEZ, Ó. J.; OSPINA, D. A.; MONTOYA, S.. Compost supplementation with nutrients and microorganisms in composting process. Waste Management, v.69, p.136-153, 2017.

SILVA, M. M. P.. Tratamentos de lodos de tanques sépticos por co-compostagem para os municípios do semiárido Paraibano: alternativa para mitigação de impactos ambientais. Tese (Doutorado em Recursos Naturais) Universidade Federal de Campina Grande, Campina Grande, 2008 .

SILVA, M. M. P.. Manual teórico metodológico de Educação Ambiental. Campina Grande: Maxgraf Ltda, 2016.

SILVA, M. M. P.. Manual de educação ambiental: uma contribuição à formação de agentes multiplicadores em educação ambiental. Curitiba: Appris Editora, 2020.

SILVA, M. M. P.; LIMA, R. A.; GOMES, R. B.; MENDES, R. A.; SANTOS SOBRINHO, J. B.; ARAUJO, E. C. S.; LIMA, V. G. S.; BARBOSA, G. F.. Educação ambiental: ferramenta indispensável à gestão municipal de resíduos sólidos. Brazilian Journal of Development, v.6, n.5, p.28743-28757, 2020.

SILVA, M. M. P.; SOUSA, M. U.; SANTOS, B. D.; COSTA, M. P.; SOARES, E. S.; RIBEIRO, L. A.; CAVALCANTE, L. P. S.. Tecnologias sociais para gestão de resíduos sólidos recicláveis secos e prevenção de riscos no exercício profissional de catadores de materiais recicláveis. Brazilian Journal of Development, v.6, n.3, p.14951-14978, 2020.

SILVA, M. M. P.; GOMES, R. B.; ARAÚJO, E. C. S.; GOMES, I.; FREITAS, A. F.; SILVA, A. V.; LEITE, V. D.. Prevalência de 
helmintos em resíduos sólidos orgânicos domiciliares; um risco à saúde ambiental e humana. Brazilian Journal of Development, v.6, n.5, p.28689-28702, 2020.

SILVA, M. M. P.; ARAÚJO E. S. A.; SOUSA, M. A.; SILVA, A. V.; SANTOS SOBRINHO, J. B.. Educação Ambiental como Instrumento de Mudança Social e Ambiental. In: CONGRESSO BRASILEIRO DE ENGENHARIA SANITÁRIA E AMBIENTAL, 30. Anais. Associação Brasileira de Engenharia Sanitária e Ambiental-ABES, 2019.

SUNDBERG, C.; FRANKE-WHITTLE, I. H.; KAUPPI, S.; YU, D.; ROMANTSCHUK, M.; INSAM, H.; JÖNSSON, H..

Characterisation of source-separated household waste intended for composting. Bioresource Technology, v.102, p.2859-2867, 2010.

SOOBHANY, N.. Preliminary evaluation of pathogenic bacteria loading on organic Municipal Solid Waste compost and vermicompost. Journal of Environmental Management, v.206, p.763-76, 2018.

SOUSA, M. U.. Gestão de resíduos sólidos sob a ótica da tecnologia social: uma experiência em Campina Grande-PB. Dissertação (Mestrado em Ciência e Tecnologia Ambiental) Universidade Estadual da Paraíba, Campina Grande, 2018.
TEDESCO, J. M.; GIANEWLLO, C.; BISSANI, C. A.; BOHENEM, H.; VOLKWEISS, S. J.. Análises de solo, plantas e outros materiais. Porto Alegre, 1995.

VALENTE, B. S.; XAVIER1, E. G.; MORSELLI, T. B. G. A.; JAHNKE, D. S.; BRUM JR.; CABRERA, B. R. P.; MORAES, P. O.; LOPES, D. C. N.. Fatores que Afetam o Desenvolvimento da Compostagem de Resíduos Orgânicos. Archivos Zootecnia, v.58, p.59-85, 2009.

VILLAMIZAR, S. C.. Avaliação da qualidade microbiológica de um composto produzido a partir de resíduos animais e vegetais. Dissertação (Mestrado em Microbiologia Agropecuária) - Universidade Estadual Paulista, Jaboticabau, 2014.

WANG, X.; CUI, H.; SHI, J.; ZHAO, X.; ZHAO, Y.; WEI, Z.. Relationship between bacterial diversity and environmental parameters during composting of different raw materials. Bioresource Technology, v.198, p.395-402, 2015.

WU, S.; XU, S.; CHEN, X.; SUN, H.; HU, M.; BAI, Z.; ZHUANG, G; ZHUANG, X.. Changes in bacterial communities during food waste deterioration. Scientific Reports, v.8, 2018.

A CBPC - Companhia Brasileira de Produção Científica (CNPJ: 11.221.422/0001-03) detém os direitos materiais desta publicação. Os direitos referem-se à publicação do trabalho em qualquer parte do mundo, incluindo os direitos às renovações, expansões e disseminações da contribuição, bem como outros direitos subsidiários. Todos os trabalhos publicados eletronicamente poderão posteriormente ser publicados em coletâneas impressas sob coordenação da Sustenere Publishing, da Companhia Brasileira de Produção Científica e seus parceiros autorizados. Os (as) autores (as) preservam os direitos autorais, mas não têm permissão para a publicação da contribuição em outro meio, impresso ou digital, em português ou em tradução. 